\title{
FERTILIDADE E RESERVAS DE CARBONO E NITROGÊNIO EM GEMAS DE RAMOS DAS VINÍFERAS 'CARBERNET SAUVIGNON' E 'NEBBIOLO'
}

\author{
ALINE MABEL ROSA ${ }^{2}$, ROSETE PESCADOR 3 , APARECIDO LIMA DA SILVA ${ }^{4}$, \\ ALBERTO FONTANELLA BRIGHENTI ${ }^{5}$, GUSTAVO BRUNETTO ${ }^{6}$
}

RESUMO - O trabalho objetivou avaliar a fertilidade e as reservas de C e N em gemas de ramos, na entrada da dormência e dormência plena, das variedades 'Cabernet Sauvignon' e 'Nebbiolo'. Em um vinhedo de 'Cabernet Sauvignon' e outro de 'Nebbiolo', em São Joaquim (SC), foram coletadas gemas em ramos de ano, em duas épocas: na entrada da dormência (maio de 2012) e na dormência plena (agosto de 2012). Os tratamentos foram: (T1) gemas basais $\left(1^{\mathrm{a}}\right.$ a $\left.5^{\mathrm{a}}\right)$; (T2) gemas medianas $\left(6^{\mathrm{a}}\right.$ a $\left.10^{\mathrm{a}}\right)$, e (T3) gemas distais $\left(11^{\mathrm{a}}\right.$ a $\left.15^{\mathrm{a}}\right)$. Em cada planta, foram coletados três ramos, um localizado no lado esquerdo, outro no lado direito e o terceiro no centro da planta. A presença ou ausência de primórdios de inflorescência foi realizada apenas nas gemas dos ramos coletados na dormência plena, usando um estereomicroscópio. Foram quantificados em gemas na entrada da dormência e na dormência plena, os teores de carboidratos solúveis totais, amido, proteínas totais, carbono orgânico total, nitrogênio total e relação C/N. A 'Cabernet Sauvignon' apresentou o maior número de gemas férteis na porção mediana dos ramos de ano. Mas, na cultivar 'Nebbiolo', o maior número de gemas férteis foi observado nas porções medianas e distais do ramo. As maiores concentrações de reservas de carbono nas gemas da 'Cabernet Sauvignon' podem ser responsáveis pela maior fertilidade de gemas. A carga de gemas férteis na 'Cabernet Sauvignon' pode ser aumentada com a poda de inverno média a longa e, na 'Nebbiolo', com poda longa, acima da $6^{\mathrm{a}}$ gema, como o Guyot.

Termos para indexação: Carbono, nitrogênio, carboidratos, Vitis vinifera L.

\section{FERTILITY AND CARBON AND NITROGEN RESERVES IN BUDS OF 'CABERNET SAUVIGNON' AND 'NEBBIOLO' GRAPEVINE SHOOTS}

\begin{abstract}
The aim of this study was to assess the fertility and $\mathrm{C}$ and $\mathrm{N}$ reserves in buds of shoots at the beginning of dormancy and complete dormancy of 'Cabernet Sauvignon' and 'Nebbiolo' varieties. In a 'Cabernet Sauvignon' and 'Nebbiolo' vineyard in São Joaquim (SC), buds were collected from new shoots at the beginning of dormancy (May 2012) and at complete dormancy (August 2012) according to the following treatments: (T1) basal buds (1st to 5th), (T2) medial buds (6th to 10th) and (T3) apical buds (11th to 15th). Three shoots were collected from each plant, one located on the left side, one on the right side and the third in the center of the plant. Determination of the presence or absence of the beginning of inflorescence was performed only in the buds collected in complete dormancy, using a stereo microscope. The contents of total soluble carbohydrates, starch, total proteins, total organic carbon, total nitrogen and $\mathrm{C} / \mathrm{N}$ ration were determined in buds at the beginning of dormancy and in complete dormancy. 'Cabernet Sauvignon' exhibited a greater number of fertile buds in the medial portion of the new shoots. But in the 'Nebbiolo' cultivar, the greatest number of fertile buds was observed in the medial and apical portions of the shoot. The greater carbon reserves in the 'Cabernet Sauvignon' buds may be responsible for the greater fertility of the buds. The fertile bud load in 'Cabernet Sauvignon' can be increased through medium to light winter pruning and in 'Nebbiolo', through light pruning above the 6th bud, as in Guyot.
\end{abstract}

Index terms: Carbon, nitrogen, carbohydrates, Vitis vinifera L.

\footnotetext{
'(Trabalho 198-13). Recebido em: 15-05-2013. Aceito para publicação em: 12-06-2014.

${ }^{2}$ Engenheira Agrônoma, Mestrando do Programa de Pós-Graduação em Fitotecnica da Universidade Federal do Rio Grande do Sul (UFRGS). E-mail: linerosa@gmail.com

${ }^{3}$ Engenheira Agrônoma, Doutora em Fisiologia Vegetal, Professora do Departamento de Fitotecnia e do Programa de Pós-Graduação em Recursos Genéticos Vegetais (PPGRGV) da Universidade Federal de Santa Catarina (UFSC). E-mail: rosete.pescador@ufsc.br ${ }^{4}$ Engenheiro Agrônomo, Doutor em Sciences Biologiques "Viticulture e Enologie", Professor do Departamento de Fitotecnia e do PPGRGV, da Universidade Federal de Santa Catarina (UFSC). E-mail: alsilva@cca.ufsc.br ${ }^{5}$ Engenheiro Agrônomo, Doutorando no PPGRGV da UFSC. E-mail: brighenti_07@hotmail.com

${ }^{6}$ Engenheiro Agrônomo, Doutor em Ciência do Solo, Professor do Departamento de Solos e do Programa de Pós-Graduação em Ciência do Solo (PPGCS), da Universidade Federal de Santa Maria (UFSM). UFSM, CCR, Departamento de Solos, Câmpus Universitário, Camobi, CEP: 97105-900, Santa Maria (RS), Brasil. E-mail: brunetto.gustavo@gmail.com (Autor para correspondência)
} 


\section{INTRODUÇÃO}

O Estado de Santa Catarina (SC) possui a quinta maior área cultivada com a videira do Brasil. Nos últimos anos, solos de altitude entre 900 e 1.400 m, no Planalto Serrano, como aqueles localizados no município de São Joaquim, passaram a ser incorporados ao sistema de produção de uvas. Normalmente, tem sido cultivadas variedades viníferas, entre elas, a 'Cabernet Sauvignon' e a 'Nebbiolo', sendo a uva destinada para a elaboração de vinhos finos. No entanto, tem-se verificado pequeno número de brotações por planta na mesma variedade e diferente entre as duas variedades, causando a diminuição drástica da produção de uva. O reduzido número de brotações está associado, provavelmente, à baixa fertilidade de gemas, que representa a capacidade de diferenciação das gemas vegetativas em frutíferas, podendo ser variável segundo a posição no ramo, ou mesmo entre ramos, como aqueles localizados nas laterais e no centro das videiras (VASCONCELOS et al., 2009).

Em videiras, as gemas latentes completamente maduras, contendo um ou mais primórdios de inflorescência, são chamadas de gemas frutíferas ou férteis. Mas, as gemas inférteis, infrutíferas ou vegetativas são aquelas latentes que contêm primórdios de gavinha no lugar de primórdios de inflorescência (BOTELHO et al., 2006). Normalmente, a fertilidade das gemas é dependente das condições climáticas, especialmente luminosidade e temperatura; do manejo, como desponta ou desbrota e do sistema de condução (SOMMER et al., 2000; LEÃO; PEREIRA, 2001; LEÃO; SILVA, 2003). A fertilidade das gemas também pode estar relacionada às suas reservas de carbono (C), como os carboidratos, acumulado nas gemas, preferencialmente na forma de amido, que pode ser convertido em açucares solúveis, estimulando a brotação no ciclo posterior (LEBON et al., 2008; CHAO; ANDERSON, 2010). Mas também, pode ser dependente do teor de proteínas e, especialmente de nitrogênio (N) (KELLER; KOBLET, 1995; VASCONCELOS et al., 2009).

O conhecimento da posição das gemas férteis em um mesmo ramo para cada variedade é determinante para se estabelecer o tipo de poda hibernal a ser realizada que, por consequência, definirá a produção de uva (TONIETTO; CZERMAINSKI, 1993; LEÃO; PEREIRA, 2001; LEÃO; SILVA, 2003). Porém, nas condições edafoclimáticas do Planalto Serrano de SC, que está tornando-se uma importante região vitivinicola do Brasil. Trabalhos sobre a fertilidade de gemas e suas reservas de C e $\mathrm{N}$ são escassos. O trabalho objetivou avaliar a fertilidade e as reservas de $\mathrm{Ce} \mathrm{N}$ em gemas de ramos, na fase de entrada e final de repouso das variedades 'Cabernet Sauvignon' e 'Nebbiolo'.

\section{MATERIAL E MÉTODOS}

O trabalho foi realizado em vinhedos comerciais, no município de São Joaquim, região do Planalto Serrano de Santa Catarina (SC). O experimento foi instalado em dois vinhedos: o vinhedo 1 , situado a $28^{\circ} 15^{\prime} 40^{\prime \prime} \mathrm{S}, 49^{\circ} 57^{\prime} 15^{\prime \prime} \mathrm{O}$ e altitude de $1.260 \mathrm{~m}$, foi da variedade 'Nebbiolo', enxertada sobre o porta-enxerto $\mathrm{SO} 4$, implantado em 2005, no espaçamento de 3,0 x 1,2 m e conduzido em espaldeira. $\mathrm{O}$ vinhedo 2 , situado a $28^{\circ} 15^{\prime} 23^{\prime \prime} \mathrm{S}, 49^{\circ} 57^{\prime} 01^{\prime \prime} \mathrm{O}$ e altitude $1.269 \mathrm{~m}$, foi da variedade 'Cabernet Sauvignon', enxertada sobre o porta-enxerto Paulsen 1103, implantado em 2002, no espaçamento de $3,0 \times 0,75 \mathrm{~m}$, sendo também conduzido em espaldeira. Os dois vinhedos foram instalados no sentido norte-sul. O solo dos vinhedos foi um Cambissolo Húmico Alumínico. O clima da região é classificado como $\mathrm{Cfb}$, segundo Köppen, e os resultados climáticos obtidos durante o período do experimento são apresentados na Tabela 1.

Os tratamentos para ambas as variedades consistiram em três regiões de coleta de gemas nos ramos de ano: (T1) gemas basais $\left(1^{\mathrm{a}}\right.$ a $\left.5^{\mathrm{a}}\right)$; (T2) gemas medianas $\left(6^{\mathrm{a}}\right.$ a $\left.10^{\mathrm{a}}\right)$, e (T3) gemas distais $\left(11^{\mathrm{a}}\right.$ a $15^{\mathrm{a}}$ ). Os ramos foram coletados em maio de 2012, correspondendo à entrada da dormência e, em agosto de 2012, quando as videiras estavam em dormência plena. Em cada planta, foram coletados três ramos: um do lado esquerdo, outro do lado direito e o terceiro no centro de cada planta. $\mathrm{O}$ delineamento experimental utilizado foi de blocos ao acaso, com 4 repetições e 12 ramos por tratamento.

Imediatamente após as coletas, as gemas nos ramos foram excisadas via corte rente ao ramo e, em seguida, cortadas longitudinalmente, de uma maneira suficiente para abri-las com o uso de uma pinça e um bisturi. A presença ou a ausência de primórdios de inflorescência foi realizada apenas nas gemas dos ramos coletados na dormência plena, usando um estereomicroscópio (Feldmann Wild Leitz SMZ 7,5), com aumento de 50 vezes. As imagens foram obtidas através de câmera fotográfica digital (Sony cybershot DSC W560), acoplada ao estereomicroscópio. Com os valores obtidos, foi estabelecido o número de gemas férteis para cada porção do ramo.

As gemas com primórdios de inflorescência, previamente verificados em estereomicroscópio, foram fixadas em solução de glutaraldeído a 2,5\%, por 24 horas, desidratadas em séries de acetona (10 
a $100 \%$ ) e secas em ponto crítico EM-CPD-030 (Leica, Heidelberg, Alemanha). Subsequentemente, as amostras foram aderidas a suportes metálicos e metalizadas (Metalizador Blatec, CED 030) com ouro. Os espécimes foram visualizados e fotografados em microscópio eletrônico de varredura (MEV) Jeol 6390 LV (JEOL Ltd., 56 Tokyo, Japan, at $20 \mathrm{kV}$ ), no Laboratório Central de Microscopia Eletrônica (LCME), da Universidade Federal de Santa Catarina (UFSC).

Foram determinados, nas gemas dos ramos coletados na entrada da dormência e dormência plena, os teores totais de carboidratos solúveis, amido, proteínas, carbono $(\mathrm{C})$ e nitrogênio $(\mathrm{N})$. Os carboidratos solúveis totais foram extraídos por tripla fervura em etanol a $80 \%$ e quantificados através de análise colorimétrica, utilizando-se do método fenolsulfúrico (DUBOIS et al., 1956). A leitura foi feita em espectrofotômetro de UV-visível, em absorbância de $490 \mathrm{~nm}$. A extração do amido foi realizada a partir do resíduo da extração dos carboidratos solúveis totais, segundo metodologia de McCready et al. (1950), e sua quantificação foi realizada de acordo com Dubois et al. (1956), em espectrofotômetro de UV-visível a $490 \mathrm{~nm}$ de absorbância. Os teores de proteínas totais foram determinados pelo método de Bradford (1976), com as modificações propostas por Read e Northcote (1981), utilizando-se do reagente azul brilhante de Coomassie R-250. A absorbância foi obtida em espectrofotômetro de UV-visível a 595 $\mathrm{nm}$ de absorbância. Os teores totais de C orgânico e $\mathrm{N}$ foram realizados de acordo com a metodologia proposta por Brunetto et al. (2008). Com os valores totais de $\mathrm{C}$ orgânico e $\mathrm{N}$ foi determinada a relação $\mathrm{C} / \mathrm{N}$. Os dados obtidos de número de gemas férteis, carboidratos solúveis totais, amido, proteínas totais, $\mathrm{C}$ orgânico total, $\mathrm{N}$ total e relação $\mathrm{C} / \mathrm{N}$ foram submetidos à análise de variância (ANOVA) e quando significativo, as médias foram comparadas pelo teste de Tukey, a 5\% de probabilidade, com o auxílio do programa ASSISTAT ${ }^{\circledR}$ versão 7.6 beta 2012.

\section{RESULTADOS E DISCUSSÃO}

A morfologia, em corte longitudinal, de gemas em ramos de ano, é apresentada nas Figuras 1a-f. As Figuras 1a e 1b são gemas da variedade 'Nebbiolo', nas quais foi possível visualizar de forma nítida a presença de primórdios de inflorescência (PI) e primórdios foliares $(\mathrm{PF})$, salientados pela seta preta, sendo, portanto, gemas férteis. O mesmo ocorreu nas Figuras c e d, cuja variedade é a 'Cabernet Sauvignon'. Ainda nesta variedade, foi visualizada por microscopia eletrônica de varredura a presença de PF e ME- meristema; GP- gema principal e GSgema secundária.

Nas variedades 'Nebbiolo' e 'Cabernet Sauvignon', nas gemas da posição mediana dos ramos de ano, coletadas na dormência plena, o complexo sistema da gema dormente foi caracterizado por uma estrutura de forma cônica, arredondada na base, com escamas nas gemas e estritamente fechadas (Figura 1a). A gema dormente consistiu em três pontos distintos de crescimento, visíveis na secção longitudinal, protegidos por pelos internamente e por escamas rígidas externamente. Os primórdios de inflorescência foram caracterizados por um eixo com inúmeras protuberâncias que se assemelham a um cacho de uva.

Em videiras, não se distinguem gemas vegetativas e gemas frutíferas, como em outras espécies frutíferas. Mas, verifica-se somente gemas mistas, que é um sistema constituído por três ápices meristemáticos, onde o meristema central primário é a gema que se abrirá na primavera posterior a sua formação (MAY, 2000). As gemas laterais, dependendo dos fatores genéticos da videira e ambientais, podem diferenciar-se em ramos no ano em que elas são produzidas; mas, normalmente, elas permanecem dormentes. Os ramos originados de gemas laterais são chamados de feminelas. Caso não aconteça a destruição das gemas primárias pelas baixas temperaturas, distúrbios fisiológicos, ataques de insetos ou patógenos, elas podem originar ramos primários em cada estação de crescimento. As gemas secundárias e terciárias tornam-se ativas apenas no caso da morte das gemas primárias e secundárias (BOTELHO et al., 2006). As gemas primárias são mais desenvolvidas e normalmente possuem vários primórdios foliares, inflorescências e gemas laterais, antes de se tornarem dormentes no final do ciclo (SMART et al., 2003). As gemas secundárias eventualmente são férteis, mas as terciárias normalmente não são férteis. $\mathrm{O}$ grau de diferenciação floral, antes do início da dormência, depende das características genéticas das variedades, do vigor do porta-enxerto, da localização da gema, bem como do ambiente circundante durante a formação das gemas (SMART et al., 2003).

Nos ramos de ano localizados na esquerda e direita (sentido Norte-Sul) da variedade 'Cabernet Sauvignon', observou-se o maior número de gemas férteis na posição média do ramo $\left(6^{\mathrm{a}}\right.$ a $10^{\mathrm{a}}$ gema $)$, que foi igual ao número de gemas férteis na posição distal ( $11^{\mathrm{a}}$ a $15^{\mathrm{a}}$ gema) (Tabela 2). As gemas basais $\left(1^{\mathrm{a}}\right.$ a $5^{\mathrm{a}}$ gema) foram as que apresentaram o menor número de gemas férteis, mas o número foi igual 
ao observado nas gemas distais. Por outro lado, nos ramos localizados no centro da videira, o número de gemas férteis foi igual na posição basal, mediana e distal do ramo. Assim, com base nos resultados obtidos, pode sugerir-se que, possivelmente, para a 'Cabernet Sauvignon' cultivada nas condições edafoclimáticas do Planalto Serrano de SC, a poda de inverno mista ou longa seja a mais adequada, o que aumentará a carga de gemas por videira (CAVALLO et al., 2001), podendo inclusive incrementar a produção de cachos de uva.

$\mathrm{Na}$ variedade 'Nebbiolo', nos ramos da esquerda, centro e direita, o maior número de gemas férteis foi verificado na posição mediana e distal (Tabela 2). Assim, sugere-se que a variedade 'Nebbiolo' seja submetida à poda de inverno longa, sendo adotado o sistema de condução Guyot, Sylvoz ou pérgola. O uso da poda longa pode aumentar a carga de gemas por planta, que aliado a um dos sistemas de condução sugerido pode promover o aumento da produção de cachos de uva (VIEIRA et al., 2006; SOZIM et al., 2007).O maior número de gemas férteis (média das gemas basais, medianas e distais)foi observado na variedade 'Cabernet Sauvignon', em relação à 'Nebbiolo' (Tabela 2). Isso provavelmente pode ser atribuído ao maior número de primórdios de inflorescência desenvolvidos nas gemas da variedade 'Cabernet Sauvignon', que é uma característica varietal e pode estar relacionado à expressão de muitos genes, que podem desencadear uma cascata de eventos que provocam a síntese e também a degradação de hormônios, como Etileno, ácido abscísico, ácido giberélico e jasmonato (BOSS et al., 2003; RAMACI et al., 2010). Por outro lado, o número de gemas férteis, na variedade 'Cabernet Sauvignon' e 'Nebbiolo', foi igual entre os ramos localizados na posição esquerda, central e direita da videira (Tabela 2). Isso aconteceu provavelmente porque o sistema de condução das videiras foi em espaldeira, o que favoreceu a penetração da radiação solar em todos os lados da planta, estimulando de forma similar a iniciação e a indução floral (SOMMER et al., 2000).

Os teores de carboidratos solúveis totais na variedade 'Cabernet Sauvignon' foram iguais entre as gemas basais, medianas e distais, na entrada da dormência e na dormência plena (Tabela 3). Mas, os teores de carboidratos solúveis totais nas gemas coletadas na dormência (média das gemas basais, medianas e distais) foram menores que os observados nas gemas coletadas na dormência plena. $\mathrm{Na}$ variedade 'Nebbiolo' e na entrada da dormência, os maiores teores de carboidratos solúveis totais foram verificados nas gemas medianas, comparativamente às gemas basais e distais (Tabela 3 ). Por outro lado, na dormência plena, os teores de carboidratos solúveis foram iguais entre as gemas basais, medianas e distais. O teor de carboidratos solúveis nas gemas (média das gemas basais, medianas e distais), na entrada da dormência, foram iguais àqueles verificados nas gemas dos ramos na dormência plena. Os teores de amido nas variedades 'Cabernet Sauvigon' e 'Nebbiolo' foram iguais entre as gemas basais, medianas e distais, na entrada da dormência e na dormência plena (Tabela 3). Mas, na variedade 'Cabernet Sauvignon', os teores de amido nas gemas (média das gemas basais, medianas e distais) dos ramos na entrada da dormência foram maiores que nas gemas dos ramos coletadas na dormência plena. Por outro lado, na variedade 'Nebbiolo', os teores de amido foram iguais entre as gemas (média das gemas basais, medianas e distais) coletadas na entrada da dormência e na dormência plena (Tabela 3).

$\mathrm{O}$ aumento do teor de carboidratos solúveis totais nas gemas dos ramos coletados na dormência plena, comparativamente às gemas dos ramos da entrada da dormência pode ser atribuído à degradação de amido, o que explica seus baixos teores nas gemas dos ramos na dormência plena (WALDIE et al., 2010). Além disso, o acúmulo de carboidratos solúveis totais normalmente é verificado nas gemas medianas dos ramos, como observado naqueles coletados na entrada da dormência, na variedade 'Nebbiolo', e pode aumentar a fertilidade das gemas, como observado nas gemas medianas da própria variedade 'Nebbiolo', mas também da 'Cabernet Sauvignon' (Tabela 2). Na variedade 'Cabernet Sauvigon', o maior teor de amido nas gemas dos ramos, na entrada da dormência, em relação àquelas da dormência plena, pode ter acontecido porque, durante a dormência plena, ocorreu aumento de temperatura do ar, o que levou, possivelmente, à ativação do metabolismo nas gemas, provocando a degradação do amido (RODRIGUES et al., 2006). Porém, isso não foi verificado na variedade 'Nebbiolo', porque as cultivares possuem características genéticas distintas (HORVATH et al., 2003).

$\mathrm{O}$ teor de proteína total, $\mathrm{C}$ orgânico e $\mathrm{N}$, que se refletiu nos valores de relação $\mathrm{C} / \mathrm{N}$, foram iguais entre as gemas basais, medianas e distais, na entrada da dormência e na dormência plena, nas variedades 'Cabernet Sauvignon' e 'Nebbiolo', o que se refletiu nos teores e valores de relação entre as gemas (média das gemas basais, medianas e distais) dos ramos na entrada da dormência e na dormência plena (Tabela 3). Os teores de proteínas totais iguais entre as gemas localizadas no mesmo ramo ou entre as gemas coletadas na entrada da dormência e 
dormência plena podem ser atribuídos à baixa taxa de degradação e mobilidade na planta em um mesmo período ou estágio fenológico, ou entre períodos ou estágios fenológicos, o que concorda com resultados obtidos por Carvalho et al. (2006), em gemas de macieira. Por outro lado, convém relatar que o $\mathrm{N}$, mas especialmente seu teor em gemas de videiras, normalmente é um dos principais responsáveis pela formação do primórdio floral e pela diferenciação das flores (KELLER; KOBLET, 1995; VASCONCELOS et al., 2009), o que poderia explicar, em parte, a baixa fertilidade das gemas dos ramos da variedade 'Nebbiolo' (Tabela 2). Porém, isso não foi verificado no presente trabalho, provavelmente porque o solo Cambissolo Húmico Alumínico do presente trabalho possui alto teor de matéria orgânica, conferindo elevada disponibilidade de $\mathrm{N}$ mineral no solo, depois da mineralização, especialmente da fração lábil da matéria orgânica; o que potencializa a utilização pela videira e, por consequência, seu incremento em órgãos da planta (BRUNETTO et al., 2008, 2009).

Os teores de $\mathrm{C}$ orgânico e a relação $\mathrm{C} / \mathrm{N}$ foram iguais entre as gemas em distintas posições no ramo ou entre as gemas coletadas nos ramos, na entrada da dormência e na dormência plena, mas verificou-se que as gemas da variedade 'Cabernet Sauvignon', na entrada da dormência e na dormência plena, apresentaram maiores teores de carboidratos solúveis totais, amido, proteínas totais, C orgânico e relação $\mathrm{C} / \mathrm{N}$, comparativamente à variedade 'Nebbiolo' (Tabela 4). Estas maiores reservas de carbono nas gemas da variedade 'Cabernet Sauvignon' podem ser uma das explicações para a maior fertilidade das gemas (Tabela 2), o que concorda com os resultados obtidos por Lebon et al. (2008).

TABELA 1- Média histórica e mensal observada da temperatura do ar, precipitação pluviométrica, umidade relativa do ar e radiação global, na área experimental. Florianópolis, 2013.

\begin{tabular}{|c|c|c|c|c|c|c|c|c|}
\hline \multirow{2}{*}{$\begin{array}{c}\text { Meses de } \\
2012\end{array}$} & \multicolumn{2}{|c|}{$\begin{array}{l}\text { Temperatura do ar } \\
\qquad\left({ }^{\circ} \mathrm{C}\right)\end{array}$} & \multicolumn{2}{|c|}{$\begin{array}{c}\text { Precipitação } \\
\text { pluviométrica }(\mathrm{mm})\end{array}$} & \multicolumn{2}{|c|}{$\begin{array}{c}\text { Umidade relativa } \\
\text { do ar }(\%)\end{array}$} & \multicolumn{2}{|c|}{$\begin{array}{l}\text { Radiação globa } \\
\left.\qquad(\mathrm{W} \mathrm{m})^{2}\right)\end{array}$} \\
\hline & $\mathrm{H}^{(1)}$ & $\mathrm{M}^{(2)}$ & $\mathrm{H}^{(1)}$ & $\mathrm{M}^{(2)}$ & $\mathrm{H}^{(1)}$ & $\mathrm{M}^{(2)}$ & $\mathrm{H}^{(1)}$ & $\mathrm{M}^{(2)}$ \\
\hline Maio & 9,3 & 9,7 & 74 & 11,2 & 91 & 88 & 139 & 150 \\
\hline Junho & 7,4 & 8,5 & 74 & 37,6 & 87 & 82 & 141 & 134 \\
\hline Julho & 8,1 & 7,5 & 107 & 0 & 85 & 84 & 141 & 133 \\
\hline Agosto & 9,9 & 11,2 & 104 & 0 & 85 & 88 & 161 & 162 \\
\hline Setembro & 9,6 & 10,7 & 151 & 0 & 87 & 85 & 190 & 196 \\
\hline
\end{tabular}

TABELA 2- Número médio de gemas férteis na posição basal ( $1^{\mathrm{a}}$ a $5^{\mathrm{a}}$ gema), mediana $\left(6^{\mathrm{a}}\right.$ a $10^{\mathrm{a}}$ gema $)$ e distal ( $11^{\mathrm{a}}$ a $15^{\mathrm{a}}$ gema), em ramos de ano posicionados no lado esquerdo, no centro e na direita (sentido norte-sul), das variedades 'Cabernet Sauvignon' e 'Nebbiolo', coletados no período da dormência, em São Joaquim (SC). São Joaquim, 2013.

\begin{tabular}{|c|c|c|c|c|c|}
\hline $\begin{array}{l}\text { Posição do ramo } \\
\text { em relação à planta }\end{array}$ & Gemas basais & Gemas medianas & Gemas distais & Média & CV (\%) \\
\hline \multicolumn{6}{|c|}{-------------------------------Cabernet Sauvignon-------------------------------- } \\
\hline Esquerda & $3,87 \pm 0,40 b^{(1)}$ & $4,50 \pm 0,73 \mathrm{a}$ & $4,12 \pm 0,61 \mathrm{ab}$ & $4,16 \mathrm{~A}^{(2)}$ & 17,12 \\
\hline Centro & $3,75 \pm 0,85 \mathrm{a}$ & $4,12 \pm 0,71 \mathrm{a}$ & $3,81 \pm 0,83 \mathrm{a}$ & $3,89 \mathrm{~A}$ & 20,18 \\
\hline Direita & $3,62 \pm 0,61 \mathrm{~b}$ & $4,43 \pm 0,51 \mathrm{a}$ & $3,87 \pm 1,02 \mathrm{ab}$ & $3,97 \mathrm{~A}$ & 17,89 \\
\hline Esquerda & $0,68 \pm 0,60 b$ & $2,87 \pm 0,61 \mathrm{a}$ & $3,12 \pm 0,95 \mathrm{a}$ & $2,22 \mathrm{~A}$ & 32,80 \\
\hline Centro & $0,56 \pm 0,62 b$ & $3,56 \pm 0,89 \mathrm{a}$ & $3,06 \pm 0,57 \mathrm{a}$ & $2,39 \mathrm{~A}$ & 28,47 \\
\hline Direita & $1,12 \pm 0,80 \mathrm{~b}$ & $3,37 \pm 0,71 \mathrm{a}$ & $3,37 \pm 0,50 \mathrm{a}$ & $2,62 \mathrm{~A}$ & 27,31 \\
\hline
\end{tabular}

(1) (2) Médias seguidas da mesma letra minúscula na linha e maiúscula na coluna, dentro de cada cultivar, não diferem entre si, pelo teste de Tukey $(\mathrm{p}<0,05)$. Dados não significativos para efeitos de interação e posição do ramo na planta. 


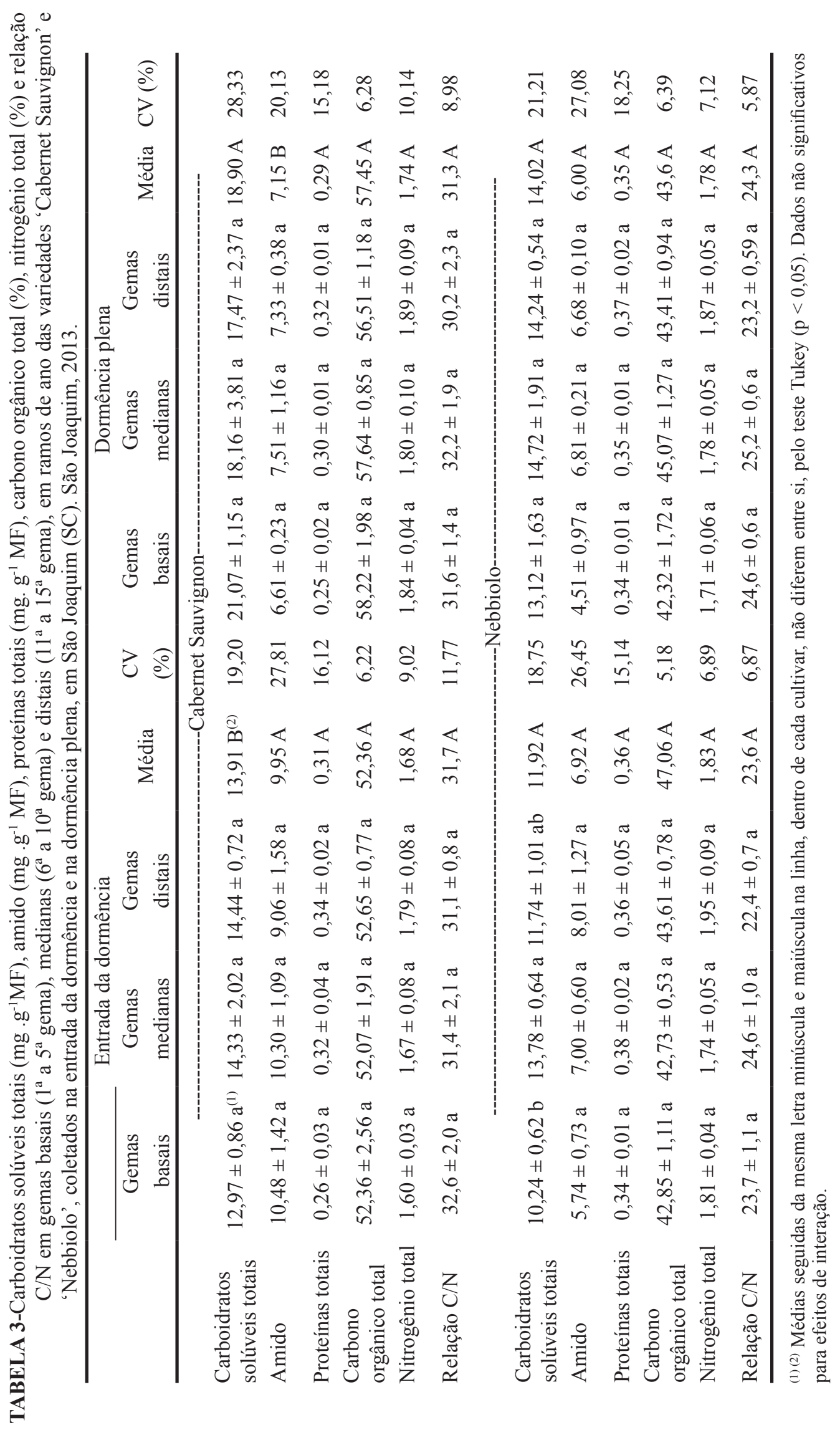



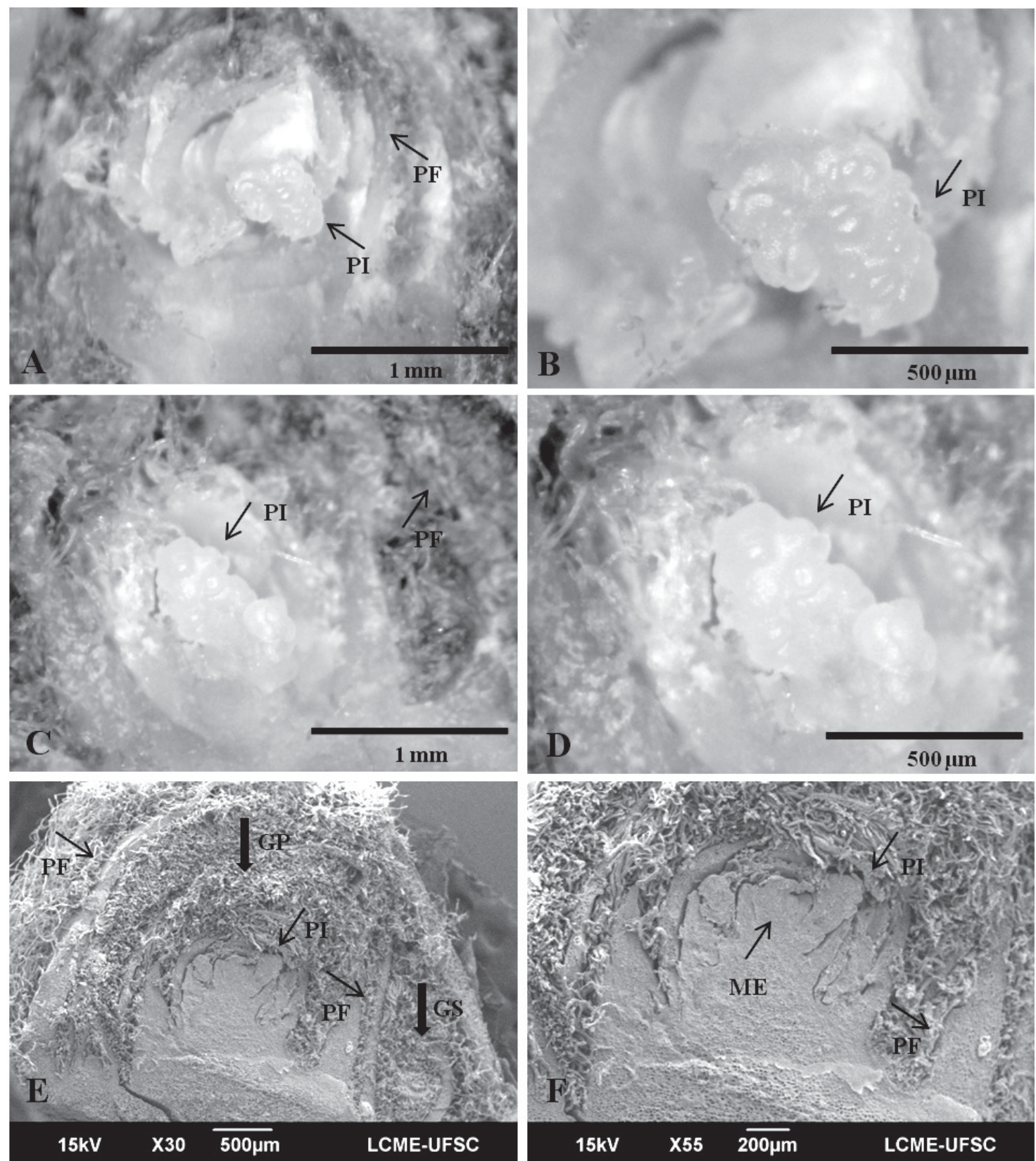

FIGURA 1- Morfologia, em corte longitudinal, de gemas em ramos de ano. a-b) gemas da variedade 'Nebbiolo'; c-d) gemas da variedade 'Cabernet Sauvignon'; e-f) gemas da variedade Cabernet Sauvignon obtidos a partir da microscopia eletrônica de varredura. A seta indica PI- primórdio de inflorescência; PF- primórdio foliar; ME- meristema; GP- gema principal e GS- gema secundária. São Joaquim, 2013. 
TABELA 4- Carboidratos solúveis totais (mg. $\left.\mathrm{g}^{-1} \mathrm{MF}\right)$, amido (mg. $\left.\mathrm{g}^{-1} \mathrm{MF}\right)$, proteínas totais (mg. $\left.\mathrm{g}^{-1} \mathrm{MF}\right)$, carbono (C) orgânico total $(\%)$, nitrogênio $(\mathrm{N})$ total $(\%)$ e relação $\mathrm{C} / \mathrm{N}$ em gemas $\left(1^{\mathrm{a}}\right.$ a $15^{\mathrm{a}}$ gema) de ramos de ano das variedades 'Cabernet Sauvignon' e 'Nebbiolo', coletados na entrada da dormência e na dormência plena, em São Joaquim (SC). São Joaquim, 2013.

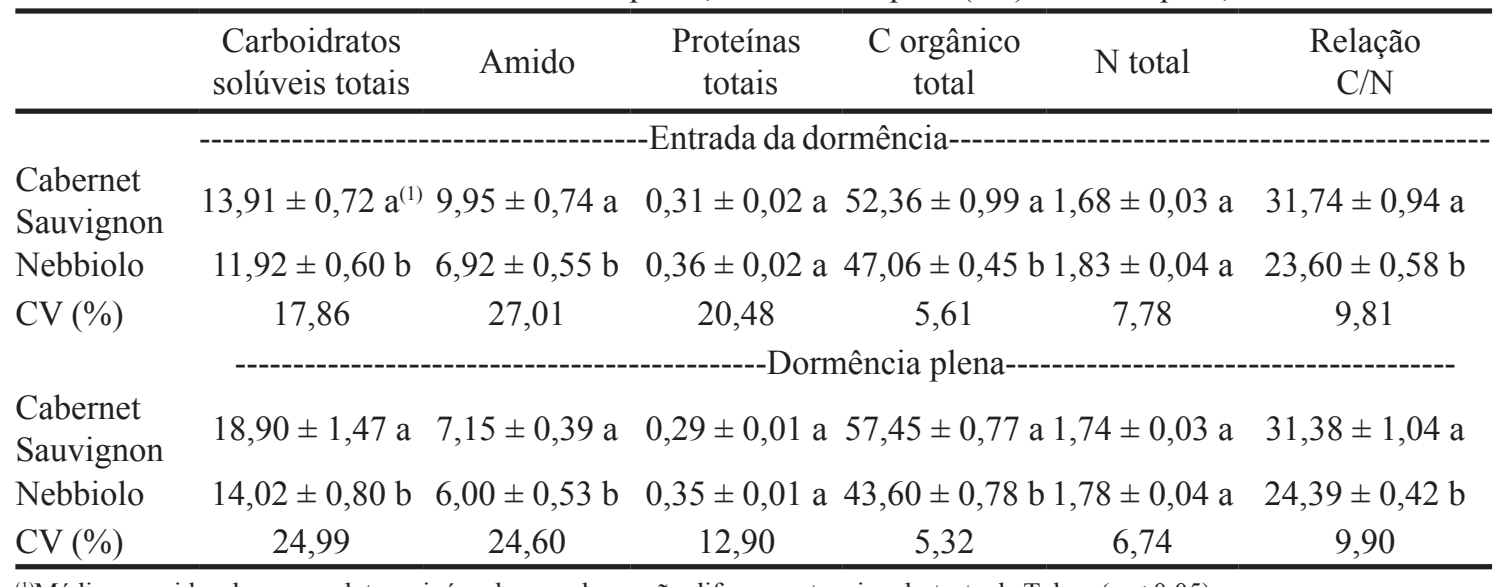

${ }^{(1)}$ Médias seguidas da mesma letra minúscula na coluna, não diferem entre si, pelo teste de Tukey $(\mathrm{p}<0,05)$.

\section{CONCLUSÕES}

1- Na 'Cabernet Sauvignon', o maior número de gemas férteis foi localizado na porção mediana dos ramos de ano, e na 'Nebbiolo', nas porções medianas e distais.

2-As maiores reservas de carbono nas gemas dos ramos de ano da 'Cabernet Sauvignon' podem ser responsáveis pela maior fertilidade de gemas.

3 - A carga de gemas férteis na 'Cabernet Sauvignon' pode ser aumentada com a poda de inverno média a longa, e na 'Nebbiolo', com poda longa, acima da $6^{\mathrm{a}}$ gema, como o Guyot.

\section{AGRADECIMENTOS}

À Fapesc e ao CNPq, pelos recursos financeiros. Ao CNPq, pela bolsa de produtividade em pesquisa concedida ao segundo e quinto autores.

\section{REFERÊNCIAS}

BOTELHO, R.V.; PIRES E.J.P.; TERRA, M.M. Fertilidade de Gemas em Videira; Fisiologia e Fatores envolvidos. Ambiência, Guarapuava, v.2, p.129-144, 2006.

BOSS, P.K.; BUCKERIDGE, E.J.; POOLE, A. New insights into grapevine flowering. Functional Plant Biology, Victoria, v.30, n.6, p.593-606, 2003.
BRADFORD, M.M. A rapid and sensitive method for the quantitation of microgram quantities of protein utilizing the principles of protein-dye binding. Analytical Biochemistry, New York, v.72, p.248254, 1976.

BRUNETTO, G.; GIROTTO, E.; MELO, G.W.B.; SANTOS, H.P.; CERETTA, C.A.; KAMINSKI, J.; VIEIRA, R.C.B. Aplicação foliar de nitrogênio em videira: avaliação do teor na folha e das reservas nitrogenadas e de carboidratos nas gemas dos ramos do ano. Revista Brasileira de Fruticultura, Jaboticabal, v.30, p.1119-1123, 2008.

BRUNETTO, G.; CERETTA, C.A.; KAMINSKI, J.; MELO, G.M.; GIROTTO. E.; TRENTIN, E.E.; LOURENZI, C.R.; VIEIRA, R.C.B.; GATIBONI, L.C. Produção e composição química da uva de videiras Cabernet Sauvignon submetidas à adubação nitrogenada. Ciência Rural, Santa Maria, v.39, p.2035-2041, 2009.

CARVALHO, R.I.N.; ZANETTE, F. Conteúdo de carboidratos em gemas e ramos de macieira durante o outono e inverno em região de baixa ocorrência de frio. Revista Brasileira de Fruticultura, Jaboticabal, v.26, p.202-205, 2004.

CARVALHO, R.I.N; ZANETTE, F.; MAURERMENESTRINA, J. Variações do conteúdo de proteínas em gemas e ramos com um e dois anos de idade de macieira durante a dormência. Revista Brasileira de Agrociência, Pelotas, v.12, p.145149, 2006. 
CAVAllo, P.; PONI, S.; ROTUNDO, A. Ecophysiology and vine performance of cv."Aglianico" under various training systems. Scientia Horticulturae, Piracicaba, v.87, p.21-32, 2001.

CHAO, W.; ANDERSON, J. V. Plant dormancy, a mechanism involving assorted molecular, physiological, and cellular processes. Plant Molecular Biology, Dordrecht, v.73, p.1-2, 2010.

DUBOIS, M.; GILLES, K.A.; HAMILTON, J.K.; REBERS, P.A.; SMITH, F. Colorimetric method for determination of sugar and related substances. Analytical Chemistry, Washington, v.28, p.350356, 1956.

HORVATH, D.P.; ANDERSON, J.V.; CHAO, W.S.; FOLEY, M.E. Knowing when to Grow: signals regulating bud dormancy. Trends in Plant Science, Oxford, v. 8, p. 534-540, 2003.

KELLER, M. W.; KOBLET. Dry matter and leaf area partitioning, bud fertility and second season growth of Vitis vinifera L.: Responses to nitrogen supply and limiting irradiance. Vitis, Siebeldingen, v.34, p.77-83, 1995.

LEÃO, P.C.S.; PEREIRA, F.M. Estudo da brotação e da fertilidade de gemas de cultivares de uvas sem sementes nas condições tropicais do Vale Submédio São Francisco. Revista Brasileira de Fruticultura, Jaboticabal, v.23, p.30-34, 2001.

LEÃO, P.C.S.; SILVA, E.E.G. Brotação e fertilidade de gemas em uvas sem sementes no Vale do São Francisco. Revista Brasileira de Fruticultura, Jaboticabal, v.25, p.375-378, 2003.

LEBON, G.; WOJNAROWIEZ, G.; HOLZAPFEL, B.; FONTAINE, F.; VAILLANT-GAVEAU, N.; CLÉMENT, C. Sugars and flowering in the grapevine (Vitis vinifera L.). Journal of Experimental Botany, Oxford, v.59, p.2565-2578, 2008.

MAY, P. From bud to berry, with special reference to inflorescence and bunch morphology in Vitis vinifera L. Australian Journal of Wine Research, Adelaide, v.6, p.82-98, 2000.
McCREADY, R.M.; GUGGOLZ, J.; SILVIERA, V.; OWENS, H.S. Determination of starch and amylose in vegetables application to peas. Analytical Chemistry, Washington, v.22, p.1.156-1.158, 1950.

RAMACI, M.N.D.; HORVATH, D.P.; CHAO, W.S.; FOLEY, M.E.; CHRISTOFFERS, M.J;ANDERSON, J.V. Low temperatures impact dormancy status, flowering competence, and transcript profiles in crown buds of leafy spurge. Plant Molecular Biology, Dordrecht, v.73, p.207-226, 2010.

READ, S.M.; NORTHCOTE, D.H. Minimization of variation in the response to different proteins of the Coomassie blue $\mathrm{G}$ dye-binding assay for protein. Anaytical Biochemistry, New York, v. 116, p.5364, 1981.

RODRIGUES, A.C.; HERTER, F.G.; VERÍSSIMO, V.; CAMPOS, A.D.; LEITE, G.B.; SILVA, J.B. Balanço de carboidratos em gemas florais de dois genótipos de Pereira 71 sob condição de inverno ameno. Revista Brasileira de Fruticultura, Jaboticabal, v.8, p. 1-4, 2006.

SMART, D.R.; KOCSIS, L.M.; WALKER, A.; STOCKERT, C. Dormant Buds and Adventitious Root Formation by Vitis and Other Woody Plants. Journal Plant Growth Regulator, Dordrecht, v.21, p.296-314, 2003.

SOMMER, K.; MUHAMMAD, T.I. ; CLINGELEFFER, P. Light and temperature effect on shoot fruitfulness in Vitis vinifera L. cv. Sultana: Influence of trellis type and graffting. Australian Journal of Grape and Wine Research, Adelaide, v.6, p.99-108, 2000.

SOZIM, M.;AYUB, R.A.; BARBOSAMALGARIM, M. Efeito do tipo de poda na produção e qualidade da videira cv. Vênus. Scientia Agraria, Curitiba, v.8, p.169-172, 2007.

TONIETTO, J.; CZERMAINSKI, A.B.C. Brotação e fertilidade das gemas da videira 'Cabernet Franc'. Revista Brasileira de Fruticultura, Jaboticabal, v.15, p.185-192, 1993.

VASCONCELOS, M.C.; GREVEN, M.; WINEFIELD, C.S.; TROUGHT, M.C.T.; RAW, V. The Flowering Process of Vitis vinifera: A Review. American Journal of Enology and Viticulture, Davis, v.60, p.411-434, 2009. 
WALDIE, T.; HAYWARD, A.; BEVEIDGE, C.A. VIEIRA, C.R.Y.; PIRES, E.J.P.; TECCHIO, M.A.; Axillary bud outgrowth in herbaceous shoots:how do strigolactones fit into the picture? Plant Molecular Biology, Dordrecht, v.73, p.27-36, 2010. OTSUBO, I.M.N.; VIEIRA, M.C.; YAMASAKI, A.K.; BORTOLZANZA, O. Fertilidade de gemas de videiras 'Niagara Rosada' de acordo com o sistema de condução. Revista Brasileira de Fruticultura, Jaboticabal, v.28, p.136-138, 2006. 